\title{
Self-(in)compatibility inheritance and allele-specific marker development in yellow mustard (Sinapis alba)
}

\author{
Fangqin Zeng $\cdot$ Bifang Cheng
}

Received: 6 February 2013/ Accepted: 10 August 2013/Published online: 22 September 2013

(C) The Author(s) 2013. This article is published with open access at Springerlink.com

\begin{abstract}
Yellow mustard (Sinapis alba) has a sporophytic self-incompatibility reproduction system. Genetically stable self-incompatible (SI) and selfcompatible (SC) inbred lines have recently been developed in this crop. Understanding the $S$ haplotype of different inbred lines and the inheritance of the self(in)compatibility (SI/SC) trait is very important for breeding purposes. In this study, we used the $S$-locus gene-specific primers in Brassica rapa and Brassica oleracea to clone yellow mustard $S$-locus genes of SI lines Y514 and Y1130 and SC lines Y1499 and Y1501. The PCR amplification results and DNA sequences of the $S$-locus genes revealed that Y514 carried the class I $S$ haplotype, while Y1130, Y1499, and Y1501 had the class II $S$ haplotype. The results of our genetic studies indicated that self-incompatibility was dominant over self-compatibility and controlled by a one-gene locus in the two crosses of Y514 $\times$ Y1499 and Y1130 $\times$ Y1501. Of the five $S$-locus gene polymorphic primer pairs, Sal-SLGI and Sal-SRKI each generated one dominant marker for the SI phenotype of Y514; Sal-SLGII and Sal-SRKII produced
\end{abstract}

Electronic supplementary material The online version of this article (doi:10.1007/s11032-013-9943-8) contains supplementary material, which is available to authorized users.

F. Zeng $\cdot$ B. Cheng $(\bowtie)$

Agriculture and Agri-Food Canada, Saskatoon Research Centre, 107 Science Place, Saskatoon, SK S7N 0X2,

Canada

e-mail: bifang.cheng@agr.gc.ca dominant marker(s) for the SC phenotype of Y1501 and Y1499; Sal-SP11II generated one dominant marker for Y1130. These markers co-segregated with the SI/SC phenotype in the $\mathrm{F}_{2}$ populations of the two crosses. In addition, co-dominant markers were developed by mixing the two polymorphic primer pairs specific for each parent in the multiplex PCR, which allowed zygosity to be determined in the $\mathrm{F}_{2}$ populations. The SI/SC allele-specific markers have proven to be very useful for the selection of the desirable SC genotypes in our yellow mustard breeding program.

Keywords Yellow mustard (Sinapis alba) . Self-(in)compatibility $\cdot$ Inheritance $\cdot S$-locus allele-specific marker $\cdot$ Marker-assisted breeding

\section{Introduction}

The tribe Brassiceae comprises many self-incompatible (SI) species, such as Brassica rapa, Brassica oleracea, Raphanus sativus, and Sinapis alba. Many genetic and molecular studies have been carried out on the self-(in)compatibility (SI/SC) mechanism in $B$. rapa and $B$. oleracea. It is now well understood that this trait is sporophytically controlled by multiple alleles of a single locus, the $S$ locus, in Brassiceae (Bateman 1955; Nasrallah and Nasrallah 1993). Three genes located in the $S$ locus, namely, $S$-receptor kinase (SRK), a female determinant, $S$-locus protein $11 / S$ locus cysteine-rich protein (SP11/SCR), a male 
determinant, and $S$-locus glycoprotein (SLG), which can enhance the SI recognition process, have been characterized (Nasrallah et al. 1988; Schopfer et al. 1999; Stein et al. 1991; Suzuki et al. 1999; Watanabe et al. 2001). As meiotic recombination between the three genes of the $S$ locus seldom occurs, a set of alleles of $S R K, S L G$, and $S P 11$, termed as the $S$ haplotype, is inherited by the progeny. About 30 and $50 S$ haplotypes have been identified in B. rapa and B. oleracea, respectively (Nou et al. 1993; Ockendon 2000). Different $S$ haplotypes have been classified into two groups, class I and class II (Nasrallah et al. 1991). Class I $S$ haplotypes are generally dominant over class II $S$ haplotypes and prevalent in B. oleracea and B. rapa (Nasrallah and Nasrallah 1993; Sato et al. 2006). Molecular studies have revealed that the DNA sequences of $S L G$ genes share a higher degree of similarity within the class I $S$ haplotypes than those between class I and class II types (Nasrallah et al. 1991).

In Brassica species, the identification of different $S$ haplotypes has been classically carried out by crossing lines with an unknown $S$ haplotype to tester lines of a known $S$ haplotype (Ruffio-Châble 1998). However, this method cannot be used to distinguish the $S$ haplotypes of partial self-compatible (SC) lines since it is based on the pollen-tube growth and seed setting. Biochemical methods have been developed to identify different $S$ haplotypes by analyzing the specific $S$ glycoproteins produced by the $S$-locus gene (Nasrallah et al. 1991; Ruffio-Châble et al. 1997). More recently, the PCR-restriction fragment length polymorphism (PCR-RFLP) technique has been successfully used as a molecular approach to identify $S$ haplotypes in B. rapa (Nishio et al. 1996), B. oleracea (Brace et al. 1993; Nishio et al. 1997), and $R$. sativus (Sakamoto et al. 1998; Lim et al. 2002). In these studies, primer pairs specific for the $S L G$ and $S R K$ genes were used to amplify the DNA fragments of different $S$ haplotypes. The resulting amplified DNA fragments exhibited different electrophoretic profiles after cleavage with restriction endonuclease(s), and these DNA fragments have proven to be useful markers for the identification of different $S L G$ or $S R K$ alleles.

Yellow mustard (S. alba) (genome: SS, $2 n=24$ ) is grown as an important condiment crop for the spice trade throughout the world. Similar to $B$. rapa and $B$. oleracea, yellow mustard is an obligate outcrossing species due to its sporophytic self-incompatibility.
However, there has been a lack of genetic and molecular studies on the SI/SC trait in this crop. Recently, different SI and SC inbred lines have been produced with the objective to develop high-yielding synthetic varieties in yellow mustard (Cheng et al. 2012). In this context, characterization of the $S$ haplotypes of different inbred lines and an understanding of the genetics of SI/SC trait are essential for breeding programs. In addition, the development of allelespecific diagnostic markers for the SI/SC phenotype will greatly increase breeding efficiency. Therefore, the objectives of our study were: (1) to clone and sequence the $S$-locus genes and classify the $S$ haplotypes of two SI and two SC inbred lines, (2) to study the inheritance of the SI/SC trait, (3) to develop $S$ locus gene allele-specific markers for marker-assisted breeding in yellow mustard.

\section{Materials and methods}

\section{Plant materials}

Two yellow mustard SI lines, Y514 and Y1130, and two SC lines, Y1499 and Y1501, were used in this study. Y514 is a doubled haploid line, and Y1130 is an inbred line developed from the breeding line W96-1-2 (Cheng et al. 2012; Javidfar and Cheng 2013). Y1499 and Y1501 are S5 inbred lines derived from the openpollinated plants Y041-1 and Y020-11 of cv. Andante, respectively. Y514 and Y1130 were crossed as the female with Y1499 and Y1501, respectively, to produce $F_{1}$ hybrid seeds. The hybridity of the $F_{1}$ plants was confirmed using molecular markers specific for each parent. The main racemes of the hybrid $F_{1}$ plants were bagged for self-pollination, while the branches were bud-pollinated to produce $\mathrm{F}_{2}$ seeds. All $F_{2}$ plants were bagged for self-pollination.

Measurement of the self-compatibility index

The self-compatibility index (SCI) (number of seeds/ self-pollinated pod) of the parental, $\mathrm{F}_{1}$, and $\mathrm{F}_{2}$ plants was measured according to Cheng et al. (2012). At least ten plants of each of the four parental lines and ten $F_{1}$ hybrid plants of each of the two crosses were measured to determine the SCI. The SI lines Y514 and Y1130 had an average SCI of 0.5 (range 0.0-1.1) and 0.05 (range 
0.0-0.1), respectively. The SC lines Y1499 and Y1501 had an average SCI of 4.2 (range 3.0-6.0) and 4.8 (range 3.2-6.9), respectively; these are similar to the seed setting (5.4 seeds/pod) of the open-pollinated plants in yellow mustard (Olsson 1974). Segregation of the SI/SC trait was studied in the $\mathrm{F}_{2}$ populations of $\mathrm{Y} 514 \times \mathrm{Y} 1499$ and $\mathrm{Y} 1130 \times \mathrm{Y} 1501$. The $\mathrm{F}_{2}$ plants were classified into two groups according to the SCI: (1) plants with a low SCI (0.0-1.2) similar to that of the SI lines Y514 and Y1130, (2) plants with a high SCI (3.0-6.4) similar to that of the SC lines Y1499 and Y1501. The $\chi^{2}$ goodness-of-fit test was used to determine the SI/SC inheritance model. All plants were grown in the greenhouse at the Agriculture and Agri-Food Canada-Saskatoon Research Centre.

Development of allele-specific markers for self(in)compatibility

Twelve $S$-locus-specific primer pairs of $B$. rapa and $B$. oleracea (Table 1 ) were used to amplify the $S$-locus genes in yellow mustard. The primer pair PS5 + PS15 (No. 1) was designed based on the DNA sequences of $S L G$ genes of class I $S$ haplotypes $S-8$ and $S-6$ in $B$. rapa and B. oleracea, respectively (Nishio et al. 1996). The primer pair PK1 + PK4 (No. 2) was designed based on the $S R K$ gene sequence of class I $S$ haplotype $S-6$ in B. oleracea and used to amplify the second to fifth exon of the $S R K$ gene (Nishio et al. 1997). The primer pair PS3 + PS21 (No. 3) is specific for the $S L G$ gene of the class II $S$ haplotype $S$-2 in B. oleracea (Nishio et al. 1996). The primer pair PK7-2II + PK82II (No. 4) is specific for the class II $S R K$ gene in $B$. rapa (Fukai et al. 2003). The SRK and SP11 gene sequences have been reported for the class II $S$ haplotypes $S$-29, $S$-44, $S$-40, and $S$-60 in B. rapa and $S-15$ in B. oleracea (Fujimoto et al. 2006; Hatakeyama et al. 1998; Kakizaki et al. 2006; Shiba et al. 2002). The conserved regions of the SRK and SPI1 genes of the above-mentioned class II $S$ haplotypes were analyzed using the CLUSTAL $\times$ program, respectively (Thompson et al. 1997). Based on the results, we designed seven primer pairs (No. 5-11) to amplify different exons and introns of the class II $S R K$ gene and one primer pair (No. 12) to amplify the $S P 11$ gene in search of polymorphic markers in yellow mustard.

The SLG, SRK, and SPI1 gene fragments were cloned and sequenced from yellow mustard lines Y514, Y1130, Y1499, and Y1501 using the primer pairs in Table 1. Based on the $S L G, S R K$, and $S P 11$ gene sequences of the four lines, we designed five primer pairs, namely, Sal-SLGI, Sal-SRKI, SalSLGII, Sal-SRKII, and Sal-SP11II (Table 2), for the generation of SI/SC allele-specific markers using Primer3 software (http://redb.croplab.org/modules/ redbtools/primer3.php). Co-segregation of the allelespecific markers with the SI and SC phenotypes was investigated in the $F_{2}$ populations from two crosses: Y514 × Y1499 and Y1130 × Y1501. In addition, a multiplex PCR mixture containing polymorphic primer pairs for the two parents was used to generate codominant markers for zygosity determinations in segregating $\mathrm{F}_{2}$ populations.

\section{DNA extraction, PCR, and DNA sequencing}

Genomic DNA was extracted from the young expanding leaves of the parental lines (Y514, Y1130, Y1499, Y1501) and $F_{1}$ and $F_{2}$ plants using a modified sodium dodecyl sulfate method (Somers et al. 1998). The PCR reaction mixture $(20 \mu \mathrm{l})$ contained $1 \times \mathrm{PCR}$ buffer, $1.5 \mathrm{mM} \mathrm{MgCl} 2,200 \mu \mathrm{M}$ of each dNTP, $0.1 \mu \mathrm{M}$ of each forward and reverse primer, $1 \mathrm{U}$ of Taq polymerase (NEB, Ipswitch, MA), and $50 \mathrm{ng}$ of genomic DNA. The PCR cycling program consisted of an initial denaturation at $94{ }^{\circ} \mathrm{C}$ for $5 \mathrm{~min}$ followed by 30 cycles of $45 \mathrm{~s}$ at $94{ }^{\circ} \mathrm{C}, 45 \mathrm{~s}$ at annealing temperature, and 1 min at $72{ }^{\circ} \mathrm{C}$, with a final extension cycle of $72{ }^{\circ} \mathrm{C}$ for $5 \mathrm{~min}$. All PCR products were analyzed by electrophoresis in $2 \%$ agarose gels in $1 \times$ TAE buffer. Gels were visualized by staining in $0.5 \mathrm{mg} / \mathrm{l}$ ethidium bromide and photographed on a digital gel documentation system. The DNA fragment of the expected PCR band was cloned with a pGEM-T kit (Promega, Madison, WI, USA), and the ligation product was transformed into competent cells (Life Technologies, Valencia, CA, USA) followed by culturing overnight at $37^{\circ} \mathrm{C}$. Positive clones containing the expected DNA fragment of the $S$-locus gene were identified by PCR analysis with M13-specific primers and were sequenced at the Plant Biotechnology Institute, National Research Council, Canada. Three to five independent positive clones containing the expected $S$-locus gene DNA fragment from each of the four yellow mustard lines were sequenced to ensure that the correct sequence was obtained. DNA sequence analysis was performed using the BLAST search tool (Blastn, NCBI). 
Table 1 Primers designed based on the sequences of the $S L G, S R K$, and SP11 genes of different $S$ haplotypes in Brassica species

\begin{tabular}{|c|c|c|c|c|c|c|}
\hline No. & Primer & Sequence $\left(5^{\prime}-3^{\prime}\right)$ & $\begin{array}{l}\text { Length } \\
\text { (bp) }\end{array}$ & Source & $S$ haplotype & Species \\
\hline \multirow[t]{2}{*}{1} & PS5 & $\begin{array}{l}\text { ATGAAAGGCGTAAGAAAA } \\
\text { ACCTA }\end{array}$ & 23 & $S L G-8(1-23)^{\mathrm{a}}$ & Class I & B. rapa \\
\hline & PS15 & $\begin{array}{l}\text { CCGTGTTTTATTTTAAGAG } \\
\text { AAAGAGCT }\end{array}$ & 27 & $S L G-6(1,336-1,310)$ & Class I & B. oleracea \\
\hline \multirow[t]{2}{*}{2} & PK1 & $\begin{array}{l}\text { CTGCTGATCATGTTCTGCC } \\
\text { TCTGG }\end{array}$ & 24 & $\begin{array}{l}\text { Second exon of } S R K \\
\text { gene }\end{array}$ & Class I & B. oleracea \\
\hline & PK4 & CAATCCCAAAATCCGAGATCT & 21 & $\begin{array}{l}\text { Fifth exon of } S R K \\
\text { gene }\end{array}$ & Class I & B. oleracea \\
\hline \multirow[t]{2}{*}{3} & PS3 & ATGAAAGGGGTACAGAACAT & 20 & $S L G-2 A(1-20)^{\mathrm{a}}$ & Class II & B. oleracea \\
\hline & PS21 & CTCAAGTCCCACTGCTGCGG & 20 & $\begin{array}{l}S L G-2 A \\
\quad(1,025-1,006)\end{array}$ & Class II & B. oleracea \\
\hline \multirow[t]{2}{*}{4} & PK7-2II & $\begin{array}{l}\text { ATGAAAAGGGTACAGAACAT } \\
\text { TTACCACC }\end{array}$ & 28 & SRK gene & Class II & B. rapa \\
\hline & PK8-2II & $\begin{array}{l}\text { CCAGTTCGGTCTCTCTTCTCA } \\
\text { CCCGAGG }\end{array}$ & 28 & SRK gene & Class II & B. rapa \\
\hline \multirow[t]{2}{*}{5} & SRKII-1L & CСACCATTCTTACACСТTCT & 20 & $\begin{array}{l}\text { First exon of } S R K \\
\text { gene }\end{array}$ & Class II & B. rapa and $B$. oleracea \\
\hline & SRKII-1R & AGATCAGCAGCATTCAATCT & 20 & $\begin{array}{l}\text { First exon of } S R K \\
\text { gene }\end{array}$ & Class II & B. rapa and $B$. oleracea \\
\hline \multirow[t]{2}{*}{6} & SRKII-2L & TACGTCAGATTGAATGCTGCTG & 22 & $\begin{array}{l}\text { First intron of } S R K \\
\text { gene }\end{array}$ & Class II & B. rapa and $B$. oleracea \\
\hline & SRKII-2R & GTAACACCACCTCGTTCATTAG & 22 & $\begin{array}{l}\text { Second exon of } S R K \\
\text { gene }\end{array}$ & Class II & B. rapa and $B$. oleracea \\
\hline \multirow[t]{2}{*}{7} & SRKII-3L & AGTTCTAATGAACGAGGTGG & 20 & $\begin{array}{l}\text { Third exon of } S R K \\
\text { gene }\end{array}$ & Class II & B. rapa and $B$. oleracea \\
\hline & SRKII-3R & GAGGAATAATAGGAGATACG & 20 & $\begin{array}{l}\text { Third intron of } S R K \\
\text { gene }\end{array}$ & Class II & B. rapa and $B$. oleracea \\
\hline \multirow[t]{2}{*}{8} & SRKII-4L & GTATCTCCTATTATTCCTCA & 20 & $\begin{array}{l}\text { Third intron of } S R K \\
\text { gene }\end{array}$ & Class II & B. rapa and $B$. oleracea \\
\hline & SRKII-4R & CACATGCGGTCATATTATTC & 20 & $\begin{array}{l}\text { Third intron of } S R K \\
\text { gene }\end{array}$ & Class II & B. rapa and $B$. oleracea \\
\hline \multirow[t]{2}{*}{9} & SRKII-5L & TAATATGACCGCATGTGCTG & 20 & $\begin{array}{l}\text { Third intron of } S R K \\
\text { gene }\end{array}$ & Class II & B. rapa and $B$. oleracea \\
\hline & SRKII-5R & TTGATGGCCTGAGAATATCC & 20 & $\begin{array}{l}\text { Third intron of } S R K \\
\text { gene }\end{array}$ & Class II & B. rapa and $B$. oleracea \\
\hline \multirow[t]{2}{*}{10} & SRKII-6L & TGTCAGCTCAAGGTACCGAT & 20 & $\begin{array}{l}\text { Third exon of } S R K \\
\text { gene }\end{array}$ & Class II & B. rapa and $B$. oleracea \\
\hline & SRKII-6R & CTGACTTCATCGAGAATGTC & 20 & $\begin{array}{l}\text { Fourth exon of } S R K \\
\text { gene }\end{array}$ & Class II & B. rapa and $B$. oleracea \\
\hline \multirow[t]{2}{*}{11} & SRKII-7L & TCCAGAATATGCGATGAACG & 20 & $\begin{array}{l}\text { Fifth exon of } S R K \\
\text { gene }\end{array}$ & Class II & B. rapa and $B$. oleracea \\
\hline & SRKII-7R & TACCGAGCGTCAATGATCGA & 20 & $\begin{array}{l}\text { Seventh exon of } S R K \\
\text { gene }\end{array}$ & Class II & B. rapa and $B$. oleracea \\
\hline \multirow[t]{2}{*}{12} & SP11II-L & TTGCATAGAGTAACCGTCTC & 20 & SP11 gene & Class II & B. rapa and $B$. oleracea \\
\hline & SP11II-R & CCGTCGTATATTGCATAGAGTA & 22 & SP11 gene & Class II & B. rapa and B. oleracea \\
\hline
\end{tabular}

SRK $S$-receptor kinase gene, SCR $S$-cysteine-rich protein gene, $S L G S$-locus glycoprotein gene, SP11 S-locus protein 11 gene

${ }^{a}$ Number in parenthesis indicates the position of the nucleotide sequence 
Table 2 Polymorphic primer pairs designed based on the DNA sequences of $S$-locus genes in yellow mustard ( $S$. alba)

\begin{tabular}{|c|c|c|c|c|c|}
\hline Primer name & Nucleotide sequences & $\begin{array}{l}\text { Annealing } \\
\text { temp }\left({ }^{\circ} \mathrm{C}\right)\end{array}$ & Size (bp) & Amplified region & Marker type \\
\hline Sal-SLGI & $\begin{array}{l}5^{\prime} \text {-ACTTCGTGATGCGAGACTCC-3' } \\
5^{\prime} \text {-CCGCGTCTTCCTCATACACC- } 3^{\prime}\end{array}$ & 68 & 626 & $\begin{array}{l}(419-438)^{\mathrm{a}} \\
(1.026-1.045)^{\mathrm{a}}\end{array}$ & Dominant \\
\hline Sal-SRKI & $\begin{array}{l}5^{\prime} \text {-GATTATCTCGTGTCTGAATG-3' } \\
5^{\prime} \text {-GGTAATGTCGAATCTCTCCT-3' }\end{array}$ & 58 & 640 & $\begin{array}{l}\text { Second intron of } S R K \text { gene } \\
\text { Fifth exon of } S R K \text { gene }\end{array}$ & Dominant \\
\hline Sal-SLGII & $\begin{array}{l}5^{\prime} \text {-GGGATTGCCTGAGTTTGTTC-3' } \\
5^{\prime} \text {-TGTCGCAATAAGCATAAGCC-3' }\end{array}$ & 60 & 310 & $\begin{array}{l}(631-650)^{\mathrm{a}} \\
(925-944)^{\mathrm{a}}\end{array}$ & Dominant \\
\hline Sal-SRKII & $\begin{array}{l}\text { 5'-TACGTCAGATTGAATGCTGCTG-3' } \\
\text { 5'-GTAACACCACCTCGTTCATTAG-3' }^{\prime}\end{array}$ & 60 & $1,000 / 1,200$ & $\begin{array}{l}\text { First intron of } S R K \text { gene } \\
\text { Second exon of } S R K \text { gene }\end{array}$ & Dominant \\
\hline Sal-SP11II & $\begin{array}{l}\text { 5'-TTGCATAGAGTAACCGTCTC-3' } \\
5^{\prime} \text {-CCGTCGTATATTGCATAGAGTA-3' }\end{array}$ & 60 & 420 & $\begin{array}{l}\text { SP11 gene } \\
\text { SP11 gene }\end{array}$ & Dominant \\
\hline
\end{tabular}

${ }^{\text {a }}$ Number in parenthesis indicates the position of the nucleotide sequence

\section{Results}

Classification of the $S$ haplotypes of Y514, Y1130, Y1499, and Y1501

The class I SLG- and SRK-specific primer pairs PS5 + PS15 (No. 1, Table 1) and PK1 + PK4 (No. 2, Table 1) amplified a 1.4- and $0.9-\mathrm{kb}$ fragment, respectively, in the SI line Y514; these were designated SalSLG-Y514 and SalSRK-Y514, respectively. However, these two primer pairs did not generate any PCR amplification in the SI line Y1130 and the SC lines Y1499 and Y1501. The class II SLG-specific primer pair PS3 + PS21 (No. 3, Table 1) produced a 1.0-kb fragment in Y1130, Y1499, and Y1501; this fragment was designated SalSLG-Y1130, SalSLGY1499, and SalSLG-Y1501, respectively. However, this primer pair failed to generate any band in Y514. Based on these PCR amplification results, we classified the $S$ haplotype of Y514 into class I and that of Y1130, Y1499, and Y1501 into class II. To further classify the class II $S$ haplotypes of Y1130, Y1499 and Y1501, we used the seven primer pairs (Nos. 4-11, Table 1) to clone the SRK gene fragments of the three lines. SRKII-2 produced two bands of 1 and $1.2 \mathrm{~kb}$ in both Y1499 and Y1501; these were designated SalSRK-Y1499alb and SalSRK-Y1501a/b, respectively. SRKII-1, SRKII-6, and SRKII-7 each generated one band of the same size, while PK7-2II + PK82II, SRKII-3, SRKII-4, and SRKII-5 showed no amplification in Y1130, Y1499, and Y1501. The class II SP11 gene-specific primer pair SP11II (No. 12,
Table 1) produced one band of $420 \mathrm{bp}$ in Y1130, designated SalSP11-Y1130, but showed no amplification in Y1499 and Y1501. Based on the PCR amplification results of the class II SRK and SP11 gene-specific primers, we inferred that the $S$ haplotype of Y1130 differed from that of Y1499 and Y1501. Cloning and sequencing of SalSLG-Y514, SalSRKY514, SalSLG-Y1130, SalSLG-Y1499, SalSLG-1501, SalSP11-Y1130, SalSRK-Y1499a/b, and SalSRK$Y 1501 a / b$ confirmed the classification of the $S$ haplotypes and provided insight into the divergence of the SC and SI alleles. SalSLG-Y514 was a 1,336-bp fragment which had $70 \%$ similarity with the class II SalSLG-Y1130, SalSLG-Y1499 and SalSLG-Y1501. SalSRK-Y514 was a 877-bp fragment. SalSLG-Y1130 consisted of $1,020 \mathrm{bp}$ and shared a similar sequence with SalSLG-Y1499 and SalSLG-Y1501, but the latter two fragments consisted of only 1,008 bp due to a 12-bp deletion at position 639. It remains to be investigated whether the SC phenotype of Y1499 and Y1501 resulted from the loss-of-function mutation due to the 12-bp deletion of the $S L G$ gene. SalSRK$Y 1499 a / b$ and SalSRK-Y1501alb shared the same DNA sequence. SalSP11-Y1130 consisted of $420 \mathrm{bp}$. Y1499 and Y1501 could have the same $S$ haplotype since they were SC and showed no difference in the DNA sequences of the cloned $S L G$ and SRK gene fragments. Therefore, we inferred that the four yellow mustard inbred lines might represent three different $S$ haplotypes: (1) Y514 carried a class I SI $S$ haplotype, (2) Y1130 had a class II SI $S$ haplotype, (3) Y1499 and Y1501 harbored a class II SC $S$ haplotype; these were 
designated Sal-S1, Sal-S2 and Sal-S3, respectively. The Sal-S1SLG, Sal-S2SLG, Sal-S3SLG, Sal-S1SRK, Sal-S3SRKa, Sal-S3SRKb, and Sal-S2SP11 sequences have been deposited in Genbank under accession codes KF355942, KF355943, KF355944, KF355945, KF355946, KF355947, KF355948, respectively.

\section{Inheritance of the SI/SC trait}

Inheritance of the SI/SC trait was studied in the two crosses of Y514 $\times$ Y1499 and Y1130 $\times$ Y1501. The SI lines Y514 and Y1130 had a low average SCI of 0.5 and 0.05 , respectively. In contrast, the SC lines Y1499 and Y1501 had a high average SCI of 4.2 (range 3.0-6.0) and 4.8 (range 3.2-6.9), respectively. The $\mathrm{F}_{1}$ plants of Y514 $\times$ Y1499 were SI with an average SCI of 0.5 (range 0.0-1.2), implying the SI $S$ haplotype of Y514 was dominant over the SC S haplotype of Y1499. The $\mathrm{F}_{2}$ plants were classified into two groups: (1) plants with a low SCI (0.0-1.2) similar to that of the SI parent Y514 and (2) plants with a high SCI (3.0-5.9) similar to that of the SC parent Y1499. The ratio of the two groups fit a single-locus gene segregation ratio of $3 \mathrm{SI}: 1$ SC $\left(\chi^{2}=0.87, P=0.35\right)$ (Fig. 1). The $\mathrm{F}_{1}$ plants derived from the cross Y1130 $\times$ Y1501 were also SI with an average SCI of 0.05 (range $0.0-0.1$ ), suggesting the dominance of SI over SC trait in this cross. In the $\mathrm{F}_{2}$ generation, plants were divided into two groups: (1) plants with a low SCI (0.0-0.3) similar to that of the SI parent Y1130 and (2) plants with a high SCI (3.2-6.4) similar to that of the SC parent Y1501. The two groups also fit well with the monogenic segregation ratio of $3 \mathrm{SI}: 1 \mathrm{SC}\left(\chi^{2}=1.11, P=0.29\right)$. These inheritance results indicated that the SI/SC trait was controlled by a one-gene locus with SI dominant over $\mathrm{SC}$ in the yellow mustard lines studied.

\section{Development and validation of the allele-specific markers for the SI/SC phenotype}

Allele-specific markers for the SI phenotype of Y514 and Y1130 Based on the sequence information of SalSLG-Y514 and SalSRK-Y514, primer pairs SalSLGI and Sal-SRKI (Table 2) were designed to generate diagnostic markers specific for the SI phenotype of Y514. The two primers each produced one dominant marker of 626 and $640 \mathrm{bp}$, respectively, in Y514, but did not generate any amplification in Y1130, Y1499, and Y1501 (Table 3). Co-segregation

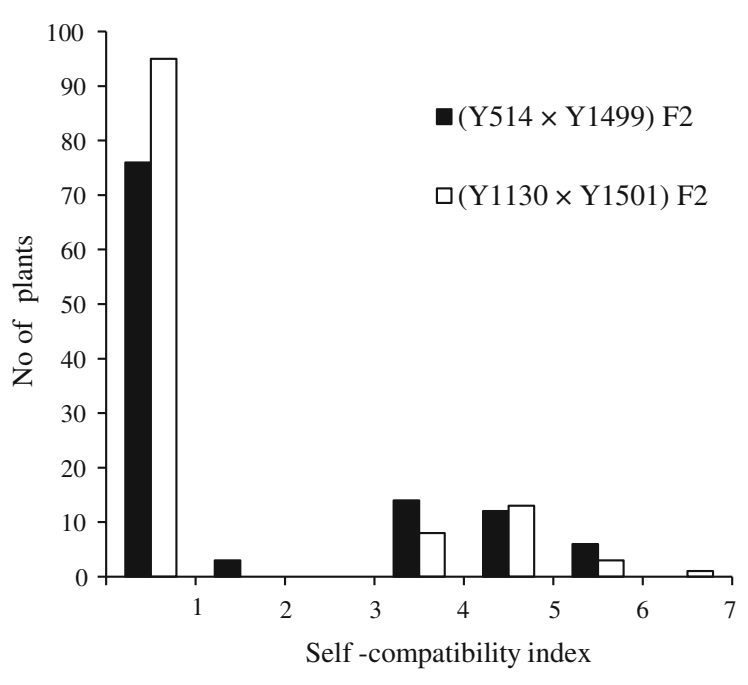

Fig. 1 Frequency distribution of self-compatibility index in the $\mathrm{F}_{2}$ populations from the crosses of yellow mustard lines $\mathrm{Y} 514 \times \mathrm{Y} 1499$ and $\mathrm{Y} 1130 \times \mathrm{Y} 1501$

of the two markers and the SI phenotype was studied in the $F_{2}$ population derived from the cross of Y514 × Y1499 (Fig. 2a). As expected, the SI allelespecific marker was present in the $F_{1}$ and all $S_{I} F_{2}$ plants, but absent in all $\mathrm{SC}_{2}$ plants. The dominant marker generated by the primer pair Sal-SRKI was linked to the SI phenotype of Y514 in the cross Y514 × Y1499 [Electronic Supplementary Material (ESM) Fig. S1A]. The primer pair Sal-SP11II generated one dominant marker of $420 \mathrm{bp}$ that was specific for Y1130 (Table 3). Co-segregation of this marker and the SI phenotype was confirmed in the $F_{2}$ population of $\mathrm{Y} 1130 \times \mathrm{Y} 1501$. The dominant marker was present in the $F_{1}$ and all $S I F_{2}$ plants, but absent in all $\mathrm{SC}_{2}$ plants (ESM Fig. S1B).

Allele-specific markers for the SC phenotype of $Y 1499$ and Y1501 The 12-bp deletion in the SLG gene fragment of Y1499 and Y1501 was used to design the SC allele-specific markers. As expected, the primer pair Sal-SLGII spanning the 12-bp deletion region generated a 310-bp fragment specific for the SC lines Y1499 and Y1501 (Table 3). Sal-SRKII revealed two polymorphic bands in Y1499 and Y1501 (Table 3). To validate the SC allele-specific markers generated by the two primer pairs Sal-SLGII and Sal-SRKII, we studied co-segregation of these markers with the SC phenotype in the two crosses of Y514 $\times$ Y1499 and Y1130 $\times$ Y1501. As indicated in ESM Fig. S1C, $F_{1}$ plants and all $\mathrm{SC} \mathrm{F}_{2}$ plants exhibited the $\mathrm{SC}$ allele- 
Table 3 The SC/SI phenotype, $S$ haplotype, and allele-specific markers of the four parental lines

\begin{tabular}{llllllll}
\hline Line & SI/SC phenotype & \multirow{2}{*}{ S haplotype } & \multicolumn{6}{l}{ Allele-specific markers for SI/SC phenotype } \\
\cline { 3 - 7 } & & & Sal-SLGI & Sal-SRKI & Sal-SLGII & Sal-SRKII & Sal-SP11II \\
\hline Y514 & SI & Class I, Sal-S1 & + & + & - & - & - \\
Y1130 & SI & Class I, Sal-S2 & - & - & - & - & + \\
Y1499 & SC & Class II, Sal-S3 & - & - & + & + & - \\
Y1501 & SC & Class II, Sal-S3 & - & - & + & + & - \\
\hline
\end{tabular}

$S C$ self-compatible, $S I$ self-incompatible, + present, - absent

specific marker produced by primer pair Sal-SLGII. The homozygote SI $F_{2}$ plants did not show any amplification. However, due to the dominance of SI over SC, the heterozygote SI $\mathrm{F}_{2}$ plants had the SC allele-specific marker and could not be distinguished from the homozygote SC genotype at the seedling stage. These results indicated that the SC allelespecific dominant markers could be useful for markerassisted selection of SC lines in yellow mustard breeding. However, co-dominant markers need to be developed in order to distinguish the homozygote SC from heterozygote SC genotypes.

\section{Development of co-dominant markers using multiplex PCR}

The development of $S$-locus gene-based co-dominant markers is essential for the determination of zygosity, which is needed in breeding programs. Multiplex PCR has proven to be a very useful molecular tool for the amplification of multiple targets in a single PCR experiment. In a multiplexing assay, more than one target sequence can be amplified through the use of multiple polymorphic primers present in the reaction mixture. In our study, we successfully developed four co-dominant markers using the multiplex PCR method. Sal-SRKI generated one dominant marker for the SI parent Y514, while Sal-SLGII and SalSRKII produced dominant marker(s) specific for the SC parents Y1499 and Y1501 (Table 3). These results indicate that including Sal-SRKI and Sal-SLGII or Sal-SRKI and Sal-SRKII in the PCR reaction would result in the production of co-dominant markers specific for each parent in the $F_{1}$ plant of Y514 $\times$ Y1499. The co-dominant markers generated by mixing Sal-SRKI and Sal-SLGII in the PCR reaction were then used for zygosity determination in the $F_{2}$ population derived from Y514 $\times$ Y 1499
(Fig. 2a). Based on this analysis, we classified these $F_{2}$ plants into three types: (1) 22 homozygote SI plants which exhibited the dominant 640-bp marker specific for Y514; (2) 57 heterozygote SI plants which showed the two markers, 640 and $310 \mathrm{bp}$, specific for Y514 and Y1499, respectively; (3) 32 homozygote SC plants which had the dominant 310-bp marker specific for line Y1499. Segregation of the three genotypes fit well with the ratio of $1: 2: 1\left(\chi^{2}=1.88, P=0.39\right)$. SalSP11II produced one dominant marker of 420 bp that was specific for Y1130. These results indicate that the PCR mixture containing Sal-SLGII and Sal-SP11II or Sal-SRKII and Sal-SP11II was able to produce codominant markers specific for both parents in the $F_{1}$ plants of Y1130 $\times$ Y1501. The co-dominant markers generated by mixing Sal-SLGII and Sal-SP11II were used to determine the zygosity of $\mathrm{F}_{2}$ plants derived from the cross Y1130 $\times$ Y1501 (Fig. 2b). Based on this analysis, we classified these $F_{2}$ plants into three groups: (1) 27 homozygote SI plants which showed the dominant marker (420 bp) of the SI parent Y1130, (2) 68 heterozygote SI plants which had markers specific for both Y1130 and Y1501, (3) 25 homozygote SC plants which had the dominant marker (310 bp) of Y1501. The segregation ratio of the three groups fit well with the segregation ratio of 1:2:1 $\left(\chi^{2}=2.2\right.$, $P=0.33)$.

\section{Discussion}

Genetically stable SI and SC inbred lines have been developed via pedigree breeding in yellow mustard (Cheng et al. 2012). In the present study, we cloned the $S L G, S R K$, and SPI1 gene fragments and then sequenced these in the four yellow mustard lines Y514, Y1130, Y1499, and Y1501 using the class I and II $S$-locus gene-specific primers from $B$. rapa and $B$. 


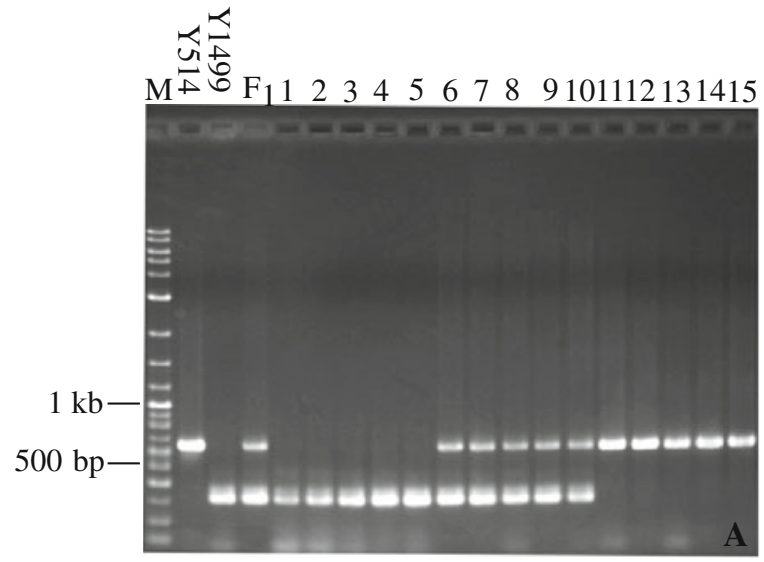

Fig. 2 Segregation of co-dominant markers and self-(in)compatibility phenotype in the $\mathrm{F}_{2}$ populations of $\mathrm{Y} 514 \times \mathrm{Y} 1499$ (a) and Y1130 × Y1501 (b). a Mixing primer pairs Sal-SRKI and Sal-SLGII in a PCR mixture generated co-dominant markers specific for Y514 and Y1499, respectively. Lanes $M$ DNA ladder, Y514 SI parent, Y1499 SC parent, $F_{1}$ plant Y514 $\times$ Y1499, 1-5 homozygote $S C F_{2}$ plants with a marker specific for the SC parent Y1499, 6-10 heterozygote SI $F_{2}$ plants with markers specific for both parents, 11-15 homozygote SI $\mathrm{F}_{2}$

oleracea. Based on the PCR amplification and sequencing results, Y514 could be classified as a class I $S$ haplotype whereas Y1130, Y1499, and Y1501 were classified as a class II $S$ haplotype. The deduced amino acid sequence of the $S L G$ gene of Y514 had only about a $60 \%$ similarity with those of Y1130, Y1499, and Y1501 (ESM Fig. S2), suggesting the occurrence of sequence divergence between class I and II $S$ haplotypes in yellow mustard, which is in agreement with earlier reported findings in $B$. rapa and B. oleracea (Nasrallah et al. 1991; Nasrallah and Nasrallah 1993). Sequence comparisons of the $S L G, S R K$, and SP11 genes between yellow mustard and Brassica species identified the corresponding $S$ haplotypes. The $S L G$ (GenBank accession no. KF355942) and SRK (GenBank accession no. KF355945) gene sequences of Y514 were 92 and $95 \%$ identical with the SLG gene (GenBank accession no. AB054734) and SRK gene (GenBank accession no. JX416335) of the class I $S$ haplotype $S$-57 in $B$. oleracea, implying that the $S$ haplotype of Y514 and S-57 in B. oleracea could be phylogenetically related. Y1130, Y1499, and Y1501 were of the class II $S$ haplotype. The $S$-locus gene sequences of these three lines were compared with those of class II $S$ haplotypes in B. rapa. The $S L G$ gene sequences (GenBank accession no. KF355943 and GenBank accession no. KF355944) of the three lines

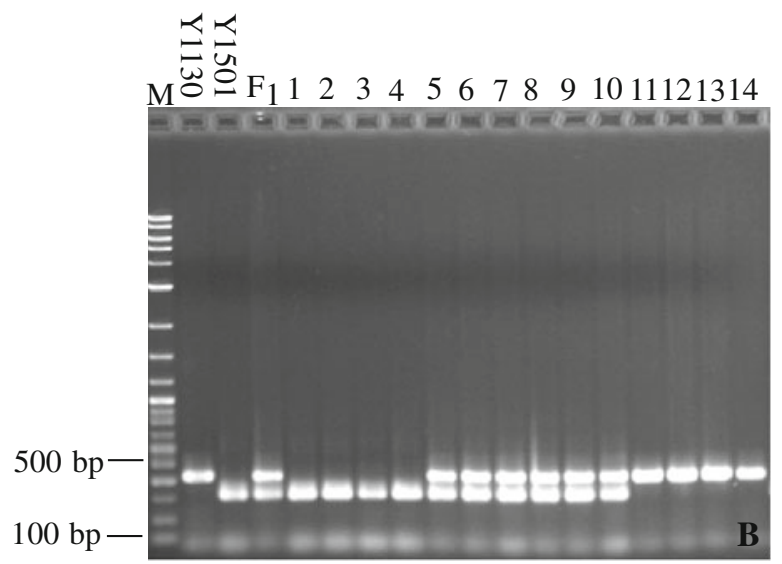

plants with markers specific for the SI parent Y514. b Mixing primer pairs Sal-SLGII and Sal-SP11II in a multiple PCR mixture generated markers specific for Y1130 and Y1501, respectively. Lanes $M$ DNA ladder, Y1130 SI parent, Y1501 SC parent, $F_{1}$ plant $\mathrm{Y} 1130 \times \mathrm{Y} 1501,1-4$ homozygote $\mathrm{SC} \mathrm{F}_{2}$ plants with a marker specific for the SC parent Y1501, 5-10 heterozygote SI $F_{2}$ plants with markers for Y1130 and Y1501, respectively, 11-14 homozygote of $\mathrm{SI}_{\mathrm{F}}$ plants with a marker specific for the SI parent Y1130

showed $92 \%$ identity to BrSLG-60 (GenBank accession no. AB097116; Fukai et al. 2003). The SRK sequences (Sal-S3SRKa and Sal-S3SRKb; GenBank accession no. KF355946 and GenBank accession no. KF355947) of Y1499 and Y1501 exhibited $89 \%$ similarity to BrSRK60 (GenBank accession no. AB097116; Fukai et al. 2003), and the SP11 gene (GenBank accession no. KF355948) of Y1130 showed $93 \%$ identity with BrSP11-60 (GenBank accession no. AB067446; Shiba et al. 2002). These results suggested that the $S$ haplotype of Y1130, Y1499, and Y1501 could correspond to class II $S$ haplotype $S$-60 in B. rapa. Compared with the class II $S$ haplotypes in $B$. oleracea, the SRK gene of Y1499 and Y1501 had $89 \%$ identity to BoSRK-15 (GenBank accession no. AB180903; Fujimoto et al. 2006), and the SP11 gene of Y1130 showed $94 \%$ similarity to BoSP11-15A (GenBank accession no. AB180904; Fujimoto et al. 2006). As expected, the deduced amino acid sequences of the S-locus genes of Y514, Y1130, Y1499, and Y1501 had a high similarity with those of their corresponding $S$ haplotypes $S-57, S-60$, and $S-15$ in Brassica species (ESM Fig. S2). This implied that the $S$ haplotype of Y1130, Y1499, and Y1501 could be related to the class II $S$ haplotype $S$ - 15 in B. oleracea. Sato et al. (2003) reported that $S-60$ in B. rapa and $S$ 15 in $B$. oleracea are phylogenetically related. 
Therefore, it is possible that the $S$ haplotype of Y1130, Y1499, and Y1501 in yellow mustard, S-60 in B. rapa, and $S-15$ in $B$. oleracea have the same evolutionary origin. Our study provides additional evidence that yellow mustard is phylogenetically related to Brassica species (Warwick and Black 1991). However, the primer pairs PK7-2II + PK8-2II, SRKII-3, SRKII-4, and SRKII-5 (Table 1), which were designed to amplify the $S R K$ gene in $B$. rapa and B. oleracea, failed to amplify the expected fragments in yellow mustard, suggesting the occurrence of divergence of the $S$ haplotypes after the speciation of yellow mustard.

The inheritance of the SI/SC trait was studied in the two crosses of Y514 $\times$ Y1499 and Y1130 $\times$ Y 1501 . The class II SC $S$ haplotype of Y1499 and Y1501 was found to be recessive to the class I and II SI $S$ haplotypes of Y514 and Y1130, respectively, and to be controlled by a one-gene locus, suggesting that the inheritance relationship between the class I and II $S$ haplotypes in yellow mustard is consistent with that reported in Brassica species (Bateman 1955; Nasrallah and Nasrallah 1993). This knowledge is of great relevance for yellow mustard breeding. The SC gene sources controlled by a single gene could be transferred into elite SI lines to develop SC varieties with improved agronomic and quality traits in yellow mustard since desirable traits can be more easily fixed in SC lines than in SI ones. This will allow the approach of commercial yellow mustard breeding programs to be switched from improving outcrossing populations to developing more uniform elite inbred line varieties. In addition, the availability of dominant and recessive SC gene sources in B. napus would allow the self-incompatibility reproduction system to be used to produce three-way hybrids (Fu 1981; Zhang et al. 2011). In such a system, the recessive SC gene source is used as maintainer (B) for the SI line while the dominant $\mathrm{SC}$ gene is used as restorer (R) line to produce $\mathrm{SC} \mathrm{F}_{1}$ hybrids. In yellow mustard, the recessive SC gene sources of Y1499 and Y1501 could be used to develop maintainers (B) for the SI lines once a dominant SC gene source has been identified and could also be used as restorer (R) line; this would allow the development of three-way hybrids.

Lines Y1499 and Y1501 had a recessive SC phenotype. Two primer pairs, Sal-SLGII and Sal-SRKII, were designed based on the DNA sequence polymorphism of the $S L G$ and $S R K$ genes and used to generate dominant markers specific for the SC phenotype of Y1499 and Y1501. We have demonstrated that the dominant markers co-segregated with the SC phenotype in the $\mathrm{F}_{2}$ populations of Y514 $\times$ Y1499 and Y1130 $\times$ Y1501. Multiplex PCR containing two polymorphic primers was used to generate co-dominant markers linked to the SI/SC trait in B. napus (Zhang et al. 2008). In our studies, we developed co-dominant markers for the SI/SC trait by mixing the two informative primers specific for SI and SC parents in the same PCR reaction mixture. These $S$-locus gene-based co-dominant markers are currently being used for marker assisted selection in our yellow mustard breeding program. In the $\mathrm{F}_{2}$ generation, the homozygote $\mathrm{SC}$ and heterozygote SI plants of interest can be identified and selected for further breeding, whereas the homozygote SI plants can be discarded at the seedling stage in the greenhouse, thereby greatly enhancing breeding efficiency.

Different inbred lines have been produced and will be used for developing high-yielding synthetic varieties in yellow mustard. Characterization of the $S$ haplotypes of different inbred lines is essential for the selection of synthetic component lines. The $S$ locus gene-specific primers developed in this study will be used to characterize the $S$ haplotypes of various elite inbred lines in yellow mustard.

Acknowledgments The condiment yellow mustard breeding and research programs have been supported by the Agriculture Development Fund (ADF) of Saskatchewan, the Developing Innovative Agri-Products Initiative of the Growing Canadian Agri-Innovations Program (DIAP), Canada and Mustard 21 Canada, Inc.

Open Access This article is distributed under the terms of the Creative Commons Attribution License which permits any use, distribution, and reproduction in any medium, provided the original author(s) and the source are credited.

\section{References}

Bateman AJ (1955) Self-incompatibility systems in angiosperms. III. Cruciferae. Heredity 9:53-68

Brace J, Ockendon DJ, King GJ (1993) Development of a method for the identification of $S$ alleles in Brassica oleracea based on digestion of PCR-amplified DNA with restriction endonucleases. Sex Plant Reprod 6:133-138

Cheng BF, Williams DJ, Zhang Y (2012) Genetic variation in morphology, seed quality and self-(in)compatibility among the inbred lines developed from a population variety in outcrossing yellow mustard (Sinapis alba). Plants 1:16-26 
Fu TD (1981) Breeding of maintainer and restorer of selfincompatible lines of Brassica napus. Cruciferae Newsl 6:40-42

Fujimoto R, Okazaki K, Fukai E, Kusaba M, Nishio T (2006) Comparison of the genome structure of the self-incompatibility $(S)$ locus in interspecific pairs of $S$ haplotypes. Genetics 173:1157-1167

Fukai E, Fujimoto R, Nishio T (2003) Genomic organization of the $S$ core region and the $S$ flanking region of a class-II $S$ haplotype in Brassica rapa. Mol Genet Genomics 269:361-369

Hatakeyama K, Takasaki T, Watanabe M, Hinata K (1998) Molecular characterization of $S$ locus genes, $S L G$ and $S R K$, in a pollen-recessive self-incompatibility haplotype of Brassica rapa L. Genetics 149:1587-1597

Javidfar F, Cheng BF (2013) Single locus, multi-allelic inheritance of erucic acid content and linkage mapping of FAE1 gene in yellow mustard (Sinapis alba L.). Crop Sci 53:825-832

Kakizaki T, Takada Y, Fujioka T, Suzuki G, Satta Y, Shiba H, Isogai A, Takayama S, Watanabe M (2006) Comparative analysis of the $S$-intergenic region in class-II $S$ haplotypes of self-incompatible Brassica rapa (syn. campestris). Genes Genet Syst 81:63-67

Lim SH, Cho HJ, Lee SJ, Cho YH, Kim BD (2002) Identification and classification of $S$ haplotypes in Raphanus sativus by PCR-RFLP of the $S$ locus glycoprotein (SLG) gene and the $S$ locus receptor kinase (SRK) gene. Theor Appl Genet 104:1253-1262

Nasrallah JB, Nasrallah ME (1993) Pollen-stigma signaling in the sporophytic self-incompatibility response. Plant Cell 5:1325-1335

Nasrallah JB, Yu SM, Nasrallah ME (1988) Self-incompatibility genes of Brassica oleracea: expression, isolation, and structure. Proc Natl Acad Sci USA 85:5551-5555

Nasrallah JB, Nishio T, Nasrallah ME (1991) The self-incompatibility genes of Brassica: expression and use in genetic ablation of floral tissues. Annu Rev Plant Physiol Plant Mol Biol 42:393-422

Nishio T, Kusaba M, Watanabe M, Hinata K (1996) Registration of $S$ alleles in Brassica campestris L. by the restriction fragment sizes of SLGs. Theor Appl Genet 92:388-394

Nishio T, Kusaba M, Sakamoto K, Ockendon DJ (1997) Polymorphism of the kinase domain of the $S$-locus receptor kinase gene $(S R K)$ in Brassica oleracea L. Theor Appl Genet 95:335-342

Nou IS, Watanabe M, Isogai A, Hinata K (1993) Comparison of $S$-alleles and $S$-glycoproteins between two wild populations of Brassica campestris in Turkey and Japan. Sex Plant Reprod 6:79-86

Ockendon DJ (2000) The $S$-allele collection of Brassica oleracea. Acta Hortic 539:25-30

Olsson G (1974) Continuous selection for seed number per pod and oil content in white mustard. Hereditas 77:197-204

Ruffio-Châble V (1998) Complexity of self-incompatibility phenotype in Brassica: its measure and some thoughts about its genetic control. Acta Hortic 459:281-288
Ruffio-Châble V, Hervé Y, Dumas C, Gaude T (1997) Distribution of the $S$-haplotypes and its relationship with selfincompatibility in Brassica oleracea. Part 1. In inbred lines of cauliflower (B. oleracea var 'botrytis'). Theor Appl Genet 94:338-346

Sakamoto K, Kusaba M, Nishio T (1998) Polymorphism of the $S$-locus glycoprotein gene $(S L G)$ and the $S$-locus related gene (SLR) in Raphanus sativus L. and self-incompatible ornamental plants in the Brassicaceae. Mol Gen Genet 258:397-403

Sato Y, Fujimoto R, Toriyama K, Nishio T (2003) Commonality of self-recognition specificity of $S$ haplotypes between Brassica oleracea and Brassica rapa. Plant Mol Biol 52:617-626

Sato Y, Sato K, Nishio T (2006) Interspecific pairs of class II $S$ haplotypes having different recognition specificities between Brassica oleracea and Brassica rapa. Plant Cell Physiol 47:340-345

Schopfer CR, Nasrallah ME, Nasrallah JB (1999) The male determinant of self-incompatibility in Brassica. Science 286:1697-1700

Shiba H, Iwano M, Entani T, Ishimoto K, Shimosato H, Che FS, Satta Y, Ito A, Takada Y, Watanabe M, Isogai A, Takayama S (2002) The dominance of alleles controlling selfincompatibility in Brassica pollen is regulated at the RNA level. Plant Cell 14:491-504

Somers DJ, Friesen KRD, Rakow G (1998) Identification of molecular markers associated with linoleic acid desaturation in Brassica napus. Theor Appl Genet 96:897-903

Stein JC, Howlett B, Boys DC, Nasrallah ME, Nasrallah JB (1991) Molecular cloning of a putative receptor protein kinase gene encoded at the self-incompatibility locus of Brassica oleracea. Proc Natl Acad Sci USA 88:8816-8820

Suzuki G, Kai N, Hirose T, Nishio T, Takayama S, Isogai A, Watanabe M, Hinata K (1999) Genomic organization of the $S$ locus: identification and characterization of genes in SLG/SRK region of $\mathrm{S}^{9}$ haplotype of Brassica campestris (syn. rapa). Genetics 153:391-400

Thompson JD, Gibson TJ, Plewniak F, Jeanmougin F, Higgins DG (1997) The Clustal_X windows interface: flexible strategies for multiple sequence alignment aided by quality analysis tools. Nucleic Acids Res 25:4876-4882

Warwick SI, Black LD (1991) Molecular systematics of Brassica and allied genera (Subtribe Brassicinae, Brassiceae)chloroplast genome and cytodeme congruence. Theor Appl Genet 82:81-92

Watanabe M, Hatakeyama K, Takada Y, Hinata K (2001) Molecular aspects of self-incompatibility in Brassica species. Plant Cell Physiol 42:560-565

Zhang XG, Ma CZ, Fu TD, Li YY, Wang TH, Chen QF, Tu JX, Shen JX (2008) Development of SCAR markers linked to self-incompatibility in Brassica napus L. Mol Breed 21:305-315

Zhang XG, Yin DM, Zhu W, Ma CZ, Fu TD (2011) Progress on characterization of self-incompatibility in Brassica napus L. Euphytica 182:147-155 